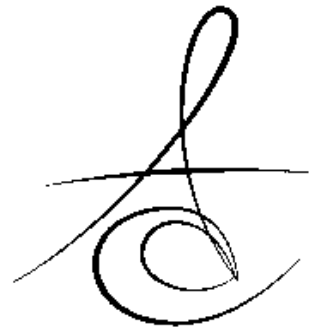

\title{
SEROMERLERİN FARKLI SOLUSYONLARDAKİ RENK DEĞİŞİMLERİNİN İNCELENMESİ ${ }^{\#}$
}

\author{
EVALUATION OF COLOR STABILITY OF CEROMERS AT DIFFERENT \\ SOLUTIONS
}

Prof. Dr. Zeynep YEŞİL DUYMUŞ*

* Arş. Grv. Dt. Ömer SAĞSöZ***

\author{
Arş. Grv. Dt. Nurdan POLAT SAĞSÖZ** \\ Prof. Dr. Funda BAYINDIR**
}

Makale Kodu/Article code: 1223

Makale Gönderilme tarihi: 03.07.2013

Kabul Tarihi: 11.09.2013

\section{ÖZET}

Rezin matriks içerisinde cam ve kuartz partikülleri içeren restoratif kompozitler, tek diş restorasyonlarında veya protetik restorasyonlarda veneer materyali olarak kullanılırlar. $\mathrm{Bu}$ yeni kompozitler yapılarındaki güçlendirme materyallerine göre fiberle güçlendirilmiş kompozit (FRC) ve seramikle güçlendirilmiş kompozit (Ceromer) olmak üzere iki ana gruba ayrılırlar.

$\mathrm{Bu}$ çalışma, seromer materyalinin farklı solüsyonlardaki renklenme özelliklerini ve renk stabilitesini değerlendirmek amacı ile yapılmıştır.

Çalışmada $5 \mathrm{~mm}$ çapında $4 \mathrm{~mm}$ yüksekliğinde hazırlanan toplam 40 seromer silindir örnek, her bir grupta rastgele seçilen sekiz örnek olacak şekilde beş gruba ayrılmıştır. Renk değerleri kaydedilen örnekler, farklı solüsyonlara (Solüsyon 1: $990 \mathrm{ml}$ yapay tükürük, Solüsyon 2: $660 \mathrm{ml}$ yapay tükürük + $330 \mathrm{ml}$ çay, Solüsyon 3: $660 \mathrm{ml}$ yapay tükürük $+330 \mathrm{ml}$ kahve, Solüsyon 4: $660 \mathrm{ml}$ yapay tükürük $+330 \mathrm{ml}$ kola, Solüsyon 5: $660 \mathrm{ml}$ yapay tükürük $+330 \mathrm{ml}$ meyve suyu) konulmuştur. Solüsyonlarda 7, 15 ve 30 gün bekletilen örneklerin renk değerleri ölçülmüş ve kaydedilmiştir. Renk değerleri renk analizi yapmak için yaygın olarak kullanılan CIE renk analiz sistemi ile saptanmıştır.

Verilerin değerlendirilmesi amacı ile varyans analizi kullanılmıştır. İçecek çeşidinin ve bekletme süresinin anlamlı olduğu $(p<0.001)$ istatistiksel olarak saptanmıştır.

Anahtar kelimeler: Seromer, renk stabilitesi, farklı solusyonlar

\section{ABSTRACT}

Restorative composites containing glass and quartz particles in the resin matrix, single-tooth restorations or prosthetic material used as veneer restorations. According to this new fiber reinforced composite materials to strengthen the structure of composites (FRC) and ceramics reinforced composite (Ceromer) to be divided into two main groups.

This study ceromer coloring material different solutions, was carried out to evaluate the properties and color stability.

In our study $5 \mathrm{~mm}$ diameter and $4 \mathrm{~mm}$ high ceromer cylindrical specimens were obtained. The samples were divided into five groups. Eight samples for each group were randomly selected. Color values of the prepared samples were recorded immediately. Then samples of each group were separately immersed in various solution (Solution 1: $990 \mathrm{ml}$ saliva, Solution 2: $660 \mathrm{ml}$ saliva $+330 \mathrm{ml}$ tea, Solution 3: $660 \mathrm{ml}$ saliva $+330 \mathrm{ml}$ coffee, Solution 4: $660 \mathrm{ml}$ saliva $+330 \mathrm{ml}$ Cola, Solution 5: $660 \mathrm{ml}$ saliva +330 $\mathrm{ml}$ fruit juice). Samples were immersed in solution 7, 15 and 30 days. Color values were measured and recorded. Color values are widely used for color analysis were determined by CIE color analysis system.

Analysis of variance was used to evaluate the data. Different of drinks and waiting time was significantly higher $(p<0.001)$ were statistically significant.

Key words: Ceromer, color stability, different solutions

* Recep Tayyip Erdoğan Üniversitesi Diş Hekimliği Fakültesi Protetik Diş Tedavisi Ana Bilim Dalı Rize

** Atatürk Üniversitesi Diş Hekimliği Fakültesi Protetik Diş Tedavisi Ana Bilim Dalı Erzurum

*** Atatürk Üniversitesi Diş Hekimliği Fakültesi Restoratif Diş Tedavisi Ana Bilim Dalı Erzurum

\# 16 th Congress of the Balkan Stomatological Society'de sunulmuştur. Bucharest, Romania, 28 April- 1

Mav 2011. 
Atatürk Üniv. Diş Hek. Fak. Derg.

] Dent Fac Atatürk Uni

Cilt:24, Sayı:1, Yıl: 2014, Sayfa: 81-84

\section{GİRIŞ̧}

Diş hekimliğine ilk girişlerinden günümüze kadar hem anterior hem de posterior restorasyonlarda yaygın olarak kullanılan kompozit rezinler ile ilgili gelişmeler kaydedilmesine karşın, polimerizasyon büzülmesi, plak birikimi, renk stabilitesinin ve fiziksel özelliklerinin iyi olmaması gibi önemli dezavantajları bulunmaktadır. ${ }^{1}$

Mekanik özellikleri geliştirmek amacı ile üretilen yeni tip kompozit rezinler içeriklerindeki güçlendirme materyallerine göre; fiber ile güçlendirilmiş (FRC) ve seramik parçacıkları ile güçlendirilmiş (seromer) olmak üzere iki ana gruba ayrılmaktadır. Fiber ile güçlendirme restorasyonlara dayanıklılık ve sertlik sağlarken, seramik ile güçlendirme dayanıklılık ve sertliğin yanında estetik özellikler kazandırmaktadır. ${ }^{2}$

Estetik bozukluklar, restorasyonların yeniden yapılmasının önemli sebeplerinden biri olarak karşımıza çıkmaktadır. Restoratif kompozitlerde klinik başarı elde edilebilmesi için; materyalin rengi ile diş rengi arasında iyi bir kombinasyonun olması gerekmektedir. ${ }^{3}$

Dişlerdeki renk değişimleri, intrensek ve ekstrensek faktörlere bağlı olarak oluşmaktadır. ${ }^{4-6}$ Ekstrensek faktörler, dışsal kaynaklara bağlı renklendiricilerin absorbsiyonu ve adsorbsiyonu ile boyanmaya neden olmaktadır. ${ }^{7,8}$

Yapılan çalışmalarda kahve, çay, kırmızı şarap ve kolanın ışık ile polimerize olan ve otopolimerizan kompozit rezin restoratif materyalleri boyama etkisi değerlendirilmiş, bu içeceklerin materyalleri kompozisyon ve özelliklerine bağlı olarak değişik derecelerde boyadığı saptanmıştır. ${ }^{9-12}$ Seromerlerde oluşan renk değişimi ile ilgili bir çalışmaya ise rastlanmamıştır.

$\mathrm{Bu}$ çalışmanın amacl, seromer materyalinin çeşitli solusyonlara değişik sürelerde maruz kaldıktan sonra renk stabilitesinin değerlendirilmesidir.

\section{MATERYAL ve METOD}

Test örnekleri renk analiz cihazının okuyucu boyutlarına uyacak şekilde $4 \mathrm{~mm}$ yüksekliğindeki teflon plakalar üzerine açılan $5 \mathrm{~mm}$ çapındaki yuvalar kullanılarak hazırlandı. Tek pat şeklindeki seromer (DE TREY GmbH 78467, Dentsply, Konstanz, Germany) materyali bu yuvalara yerleştirildikten sonra selüloit bant altında ışık (Dentamerica, CA,USA) ile 40 sn polimerize edildi. Örneklerdeki fazlalıklar alındıktan sonra yüzeylerine disk (Soflex: 3M Dental Product USA) ile bitirme işlemi uygulandı. Hazırlanan 40 örnek
YEŞİL DUYMUŞ, POLAT SAĞSÖZ, SAĞSÖZ, BAYINDIR

eşit sayıda (8 örnek) olacak şekilde 5 alt gruba ayrıldı. Numaralanan örneklerin renk değerleri CIE tarafından hazırlanan test standardı esas alınarak hazırlanan kolorimetre (Shade Eye NCC; Shofu Dental Corporation, Kyota, Japan) ile kaydedildi (Resim 1). Kolorimetre her ölçümden önce üreticinin tavsiyelerine göre kalibre edildi. Tüm veri kayıtları, teknik farklılıkları minimize etmek amacıyla aynı gözlemci tarafından beyaz zemin üzerinde yapıldı. Daha sonra örnekler, aşağıdaki solüsyonlara konuldu.

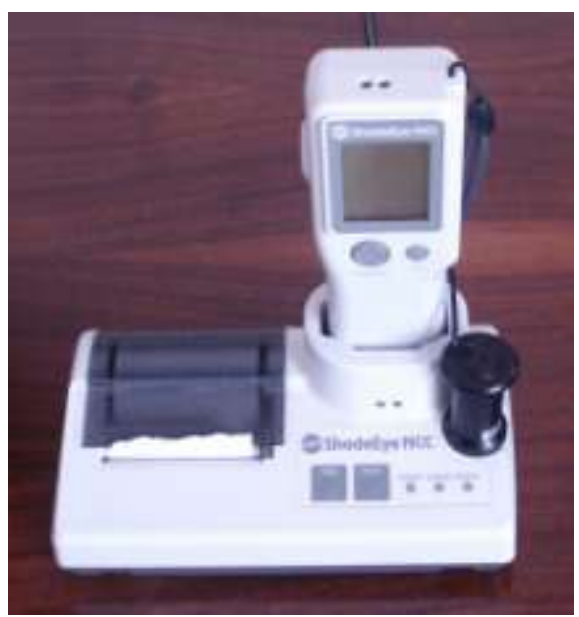

Resim 1. Renk ölçümlerinin yapıldığı cihaz.

- Solüsyon 1: 990ml yapay tükürük (1.47 g KCL, $\mathrm{NaHCO}_{3}, 1.25 \mathrm{~g} \mathrm{KSNC}, 0.52 \mathrm{~g} 0.19 \mathrm{~g} \mathrm{NaH} \mathrm{PO}_{4} \cdot \mathrm{H}_{2} \mathrm{O}$, distile su)

- Solüsyon 2: $660 \mathrm{ml}$ yapay tükürük + $330 \mathrm{ml}$ çay

- Solüsyon 3: $660 \mathrm{ml}$ yapay tükürük + $330 \mathrm{ml}$ kahve (5-6 g/65 ml, Kurukahveci Mehmet Efendi, Türk Kahvesi T.M., İstanbul,Türkiye)

- Solüsyon 4: $660 \mathrm{ml}$ yapay tükürük + $330 \mathrm{ml}$ kola

- Solüsyon 5: $660 \mathrm{ml}$ yapay tükürük + $330 \mathrm{ml}$ meyve suyu

Solüsyonlarda bekletilen örnekler 7,15 ve 30 . günde çıkarılıp akan su altında yıkanıp kurutulduktan sonra renk değerleri tekrar kaydedildi.

Renk farklılıkları aşağıdaki formül kullanılarak hesaplandı.

$\Delta \mathrm{E}^{*} \mathrm{ab}=\left\{\left(\Delta \mathrm{L}^{*}\right) 2+\left(\Delta \mathrm{a}^{*}\right) 2+\left(\Delta \mathrm{b}^{*}\right) 2\right\} 1 / 2$

$\Delta \mathrm{L}^{*}=\mathrm{L} * \mathrm{O}-\mathrm{L} * \mathrm{t}$

$\Delta \mathrm{a} * \mathrm{a} * \mathrm{o}-\mathrm{a} * \mathrm{t}$

$\Delta \mathrm{b} *=\mathrm{b} * \mathrm{o}-\mathrm{b} * \mathrm{t}$

$\mathrm{L} * \mathrm{t}, \mathrm{a} * \mathrm{t}, \mathrm{b} * \mathrm{t}$ : bekletmeden önce

$\mathrm{L}^{*} \mathrm{o}, \mathrm{a}^{*} \mathrm{o}, \mathrm{b}{ }^{*} \mathrm{o}$ : beklettikten sonra

Elde edilen sonuçlar Repeated Measures

Analysis of Varience ( ANOVA) ve Duncan çoklu

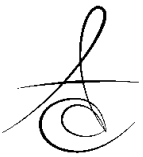


Atatürk Üniv. Diş Hek. Fak. Derg.

J Dent Fac Atatürk Uni

Cilt:24, Sayı:1, Yıl: 2014, Sayfa: 81-84

karşılaştırma testleri ile istatistiksel olarak değerlendirildi.

\section{BULGULAR}

Yapılan iki yönlü varyans analizi sonucunda; farklı içecek tiplerinde değişik sürelerde bekletilen örneklerde elde edilen $\Delta \mathrm{E}$ değerleri arasındaki farkın anlamlı olduğu $(p<0.001)$ istatistiksel olarak saptandı.

Çoklu karşılaştırma testi sonucunda;

- Kontrol grubu olarak kullanılan yapay tükürükte bekletilen örneklerde de başlangıç renginden renk farklılı̆ı olduğu,

- tüm grupların boyama kapasitesinin kontrol grubundan farklı olduğu,

- kahve solusyonunun diğer gruplardan daha kromojenik olduğu,

- çay, kola ve meyve suyunda bekletilen örneklerin renk değişikliklilerinin benzer olduğu saptandı (Tablo 1).

Tablo 1. Farklı solüsyonlar içindeki örneklerin zamana bağlı $\Delta \mathrm{E}$ değerlerinin ortalama, standart sapma ve Duncan çoklu karşılaştırma testi sonuçları $(\mathrm{N}=8)$.

\begin{tabular}{|l|l|l|l|l|l|l|}
\hline \multirow{2}{*}{ İçecekler } & \multicolumn{2}{|l|}{ 7. gün $\left(\Delta \mathrm{E}_{1}\right)$} & \multicolumn{1}{l|}{$\begin{array}{l}15 . \\
\left(\Delta \mathrm{E}_{2}\right)\end{array}$} & \multicolumn{2}{l|}{ gün } & \multicolumn{2}{l|}{ gün $\left(\Delta \mathrm{E}_{3}\right)$} \\
\cline { 2 - 7 } & $\mathrm{X}$ & $\mathrm{Sd}$ & $\mathrm{X}$ & $\mathrm{Sd}$ & $\mathrm{X}$ & $\mathrm{Sd}$ \\
\hline Yapay Tükürük & $2,16^{\mathrm{a}}$ & 1,20 & $2,18^{\mathrm{a}}$ & 1,32 & $2,23^{\mathrm{a}}$ & 1,63 \\
\hline $\begin{array}{l}\text { Yapay Tükürük+ } \\
\text { Çay }\end{array}$ & $3.05^{\mathrm{b}}$ & 2,52 & $3,77^{\mathrm{b}}$ & 1,45 & $5,15^{\mathrm{bc}}$ & 1,73 \\
\hline $\begin{array}{l}\text { Yapay Tükürük+ } \\
\text { Kahve }\end{array}$ & $5,05^{\mathrm{d}}$ & 2,39 & $6,69^{\mathrm{de}}$ & 2,55 & $7,51^{\mathrm{df}}$ & 2,13 \\
\hline $\begin{array}{l}\text { Yapay Tükürük + } \\
\text { Kola }\end{array}$ & $2,64^{\mathrm{b}}$ & 1,30 & $2,71^{\mathrm{b}}$ & 1,27 & $3,21^{\mathrm{bc}}$ &, 60 \\
\hline $\begin{array}{l}\text { Yapay Tükürük + } \\
\text { Meyve suyu }\end{array}$ & $2,58^{\mathrm{b}}$ & 1,21 & $2,52^{\mathrm{b}}$ & 1,17 & $3,29^{\mathrm{bc}}$ & 1,21 \\
\hline
\end{tabular}

\section{TARTIŞMA}

Renklenme, kolorantların restoratif materyallerin yüzeyine absorbe ve adsorbe olması ile meydana gelmektedir. Çaydaki kolorantların sadece yüzeye absorbe olduğu, kahvedeki kolorantların ise hem absorbsiyon hem de adsorbsiyonla renk değişimi oluşturduğu bildirilmiştir. ${ }^{13}$ Um ve Ruyter ${ }^{4}$ kahvedeki kolorantlarının yüzeye yapıştıktan sonra sabit kalıp, çaydaki kolorantların ise uzaklaştığı bu nedenle kahvedeki boyanmanın daha fazla olduğunu ifade etmişlerdir. Khoklar ve arkadaşları ${ }^{14}$ kompozit rezinlerdeki renk değişiminin, çayda bekletilen örneklerde kahvede bekletilen örneklerden daha fazla olduğunu saptamışlardır. Bu çalışmada ise kahvenin boyama özelliğinin daha fazla olduğu tespit edilmiştir. İki araş-
YEŞİL DUYMUŞ, POLAT SAĞSÖZ, SAĞSÖZ, BAYINDIR tırmanın sonuçları arasındaki fark kullanılan materyallerin bileşimlerinin farklı olmasından kaynaklanmış olabilir.

Mundim ve arkadaşları ${ }^{15}$ Coca Cola'nın içeriğindeki fosforik asite rağmen kompozitlerin renk değişikliğinde etkili bir içecek olmadığını, aksine içerisindeki fosfat iyonlarının dişten kalsiyum fosfatın çözünme oranını azalttığını ifade etmişlerdir. Çalışmaları sonucunda kola ve distile suda bekletilen örneklerde oluşan renk değişimleri arasındaki farkın anlamlı olmadığını, kahvede bekletilen örneklerdeki renk değişiminin ise anlamlı olduğunu istatistiksel olarak saptamışlardır.

Topcu ve arkadaşları ${ }^{3}$ kullanmış oldukları farklı solusyonlar içerisinde kahve ve kırmızı şarabın diğer solüsyonlardan daha fazla renk değişikliğine sebep olduğunu tespit etmişlerdir.

Bu çalışmada yapay tükürükte bekletilen örneklerin de zamanla renk değişimi gösterdiği saptanmıştır. Bu durum polimerin yapay tükürük içerisindeki bileşenleri absorbe etmesine bağlanabilir. Araştırma sonucunda en fazla renk değişiminin kahvede bekletilen örneklerde olduğu, çay, meyve suyu ve kolada bekletilen örneklerin ise benzer renk değişimi gösterdiği saptanmıştır. Kullanılan içeceklerin boyama değerlerinin bekletme süresine bağlı olarak arttığı saptanmıştır.

Ertaş ve arkadaşları $^{6}$ çalışmaları sonucunda restoratif materyal ve bekletme solusyonu çeşidinin, bunlar arasındaki etkileşimin renk değişikliğinde önemli rol oynadığını saptamışlardır. Bu çalışmada da benzer sonuçlar elde edilmiştir. Ayrıca Ertaş ve arkadaşları ${ }^{6}$ çay, kahve ve kırmızı şarapta bekletilen örneklerdeki renk değişikliğinin görsel olarak algılandığını bu durumunda klinik olarak kabul edilemez olduğunu bildirmişlerdir.

Restoratif materyallerin yüzey özellikleri ve boyayıcı solusyonların tipi renk stabilitesi üzerinde etkilidir. Bitirme ve cila işlemleri boyanmayı azaltıp, restorasyonun ömrünü artırmaktadır. ${ }^{13,16} \mathrm{Bu}$ çalışma$\mathrm{da}$, bitirme işlemleri standart bir şekilde cila diskleriyle sırasıyla uygulanarak, örneklerin yüzeyinin düzgün olması sağlanmıştır. Restoratif rezinlerin renk stabilitesini; saklama solusyonlarının $\mathrm{pH}^{\prime} ı n ı n$, ultraviole ışık radyasyonunun, kompozit rezinlerin içeriğindeki amin miktarının ve tipinin, inhibitörlerin, ${ }^{17}$ ayrıca kişinin diet ve oral alışkanlıklarının, manipülasyon tekniklerinin, polimerizasyon yönteminin, ışık aktivasyonundan sonra kalan rezidüel HEMA'nın, su emiliminin ve uygulama esnasındaki nem kontaminasyonunun etkilediği de ifade edilmiştir. ${ }^{18}$ 
Atatürk Üniv. Diş Hek. Fak. Derg.

J Dent Fac Atatürk Uni

Cilt:24, Sayı:1, Yıl: 2014, Sayfa: 81-84
YEŞİL DUYMUŞ, POLAT SAĞSÖZ, SAĞSÖZ, BAYINDIR
Tunçdemir ve arkadaşları ${ }^{19}$ farklı renklendirici solusyonlar (çay, kahve ve kola) içerisindeki seromerlerin, hibrit kompozit ve seramiklere göre renk stabilitesini karşılaştırdıkları çalışma sonucunda, incelenen estetik materyaller arasında en fazla renk değişiminin seromerlerde olduğunu, en fazla renklendirici ajanın ise kahve olduğunu belirlemişlerdir.

\section{SONUÇ}

Kompozit rezinlerin uzun süreli kullanımında renklenme sorunu ile karşılaşılmaktadır. Seramikle güçlendirilen kompozitlerde de bu problemin olup olmadığının araştırıldığı bu çalışma sonucunda; seromer materyalinin renk stabilitesinin çeşitli solusyonlardan etkilendiği, renk değişimi üzerinde en etkili içeceğin kahve olduğu, çay, kola, meyve suyu ve kontrol amacı ile kullanılan distile suda daha az renklenme meydana geldiği, boyanma değerlerinin bekletme süresinden etkilendiği saptanmıştır.

\section{KAYNAKLAR}

1. Stober T, Gilde H, Lenz P. Color stability of highly filled composite resin materials for facings. Dental Mater 2001; 17:87-94.

2. Freilich MA, Meiers JC, Duncan JP, Eckrote KA, Goldberg AJ. Clinical evaluation of fiber-reinforced fixed bridges. J Am Dent Assoc 2002;133:1524-34.

3. Topcu FT, Sahinkesen G, Yamanel K, Erdemir U, Aybala Oktay $E$, Ersahan S. Influence of different drinks on the colour stability of dental resin composites. Eur J Dent 2009;3:50-6.

4. Um CM, Ruyter IE. Staining of resin-based veneering materials with coffee and tea. Quintessence Int 1991; 22:377-86.

5. Yannikakis SA, Zissis AJ, Polyzois GL, Caroni C. Colour stability of provisional resin restorative materials. J Prosthet Dent 1998;80:533-9.

6. Ertaş $E$, Güler $A U$, Yücel $A C$, Köprülü $H$, Güler $E$. Color stability of resin composites after immersion in different drinks. Dental Materials Journal 2006;25:371-6.

7. Satou N, Khan AM, Matsumae I, Satou J, Shintani $\mathrm{H}$. In vitro colour change of composite- based resins. Dent Mater 1989;5:384-7.

8. Raptis CN, Powers JM, Fan PL, Yu R. Staining of composite resins by cigarette smoke. J Oral Rehabil 1982;9:367-71.
9. Türkün LS, Türkün M. Effect of bleaching and repolishing procedures on coffee and tea stain removal from three anterior composite veneering materials. J Esthet Restor Dent 2004; 16:290-301.

10. Borges $A B$, Marsilio $A L$, Pagani $C$, Rodrigues JR. Surface roughness of packable composite resins polished with various systems. J Esthet Restor Dent 2004;16:42-7.

11. Guler AU, Yilmaz F, Kulunk T, Guler E, Kurt S. Effects of different drinks on stainability of composite resin provisional restorative materials. J Prosthet Dent 2005: 94:118-24.

12. Bagheri R, Burrow MF, Tyas M. Influence of foodsimulating solutions and surface finish on susceptibility to staining of aesthetic restorative materials. J Dent 2005; 33: 389-98.

13. Köprülü H, Dayangaç B, Gürgan S, Önen A. Farklı posterior kompozitlerin kahve ve çay ile boyanması. A Ü Diş Hek Fak Derg 1992;19:371.

14. Khokhar ZA, Razzoog ME, Yaman P. Color stability of restorative resins. Quintessence Int 1991;22:733-7.

15. Mundim FM, Garcia Lda F, Pires-de-Souza Fde C. Effect of staining solutions and repolishing on color stability of direct composites. J Appl Oral Sci 2010;18:249-54.

16. Chan KC, Fullen JL, Hormati AA: The ability of foods to stain two composite resins. J Prosthet Dent 1980;43:542-5.

17. Hosoya Y. Goto G. Color changes of light cured composite resins. J Clin Pediatr Dent 1992;16:24752.

18. Inokoshi S, Burrow MF, Katsumi M, Yamada T, Takatsu T. Opacity and color changes of tooth colored restorative materials. Oper Dent 1996; 21:73-80.

19. Tunçdemir AR, Kara HB, Aykent F. Comparison of Ceromers Color Stability to Hybrid Composites and Ceramics After Immersion in Different Beverages. Türkiye Klinikleri J Dental Sci 2012;18:163-9.

\section{Yazışma Adresi:}

Prof. Dr. Zeynep YEŞİL DUYMUŞ

Recep Tayyip Erdoğan Üniversitesi

Diş Hekimliği Fakültesi -Rize

E mail: zyesilz@hotmail.com 